\title{
Descriptive Analysis of Articles and Advertisements Pertaining to Skin Cancer Prevention in 2 Popular US Parenting Magazines, 2000-2010
}

Corey H. Basch, EdD, MPH; Grace Clarke Hillyer, EdD, MPH; Charles E. Basch, PhD

Suggested citation for this article: Basch CH, Hillyer GC, Basch CE. Descriptive Analysis of Articles and Advertisements Pertaining to Skin Cancer Prevention in 2 Popular US Parenting Magazines, 2000-2010. Prev Chronic Dis 2013;10:120200. DOI: http://dx.doi.org/10.5888/pcd10.120200 通.

PEER REVIEWED

\section{Abstract}

Magazines focused on parenting are popular in the United States, and parents may use them to guide decisions about the health of their children. We analyzed issues of 2 popular parenting magazines published in the past 11 years during the months of peak ultraviolet radiation exposure for content related to sun protection and for advertisements for skin products that did and did not contain sun protection factor. Only 24 of 2,594 articles addressed the topic of sun protection for skin cancer prevention. Although advertising is pervasive in these magazines, the extent to which such advertising focuses on products with sun protection factor was low. These findings suggest that parenting magazines can do more to assist parents in making informed decisions about preventing skin cancer risk among youth.

\section{Objective}

Skin cancer is the most common form of cancer in the United States (1). Excessive exposure to ultraviolet radiation at a young age contributes to the risk of developing melanoma later in life (2). Parents play a crucial role in minimizing their children's excessive exposure to ultraviolet radiation and in instilling life-long protective habits $(3-5)$.

Parents and Parenting are the 2 most popular US magazines that target parents, comprising more than 4 million subscriptions and a combined readership of approximately 24 million in 2011 (6). We assessed a sample of these publications to describe the prevalence of articles and advertisements related to skin cancer prevention.

\section{Methods}

We used direct observation to identify articles and advertisements related to skin, skin care, and health in the spring and summer issues (May, June, July, and August) of Parents and Parenting magazines during an 11-year period (2000 -2010). Because the magazines had to be viewed in their entirety, only fully intact, hard copies of magazines or complete versions of microfilm could be used. Articles related to skin, skin care, and health were identified from the table of contents and examined. Each article was read, and word counts were conducted on all articles; content was assessed in terms of the type of information that each article contained. Articles about skin were grouped into 3 categories: "sun protection," "beauty-related," and "other" (eg, moles, rashes). During the coding process, we used a coding sheet for each issue that had space to record content, word count, and the types of advertisements contained in the issue.

The total number and type of all advertisements were recorded by reviewing each page of the magazine. Special notation was made for advertisements related to sunless tanning products, sun block, and skin products, both with and without sun protection factor (SPF). Although many categories of advertisements were related to varied products and services, we report only those related to skin and health in general. Health advertisements were coded as "adult health" (eg, birth control), "child health" (eg, medication for attention-deficit/hyperactivity disorder), and "miscellaneous health," which was not aimed specifically at adults or children (eg, dental care products). We examined the frequency of articles and 
advertisements devoted to skin and health relative to all articles and advertisements. Ranges for each item were also calculated.

\section{Results}

Of the 2,594 articles reviewed (range, 181-290 per year observed), 57 (2.2\%) were related to skin and 509 (19.6\%) were related to health (Table). Of the skin-related articles, 24 (42.1\%) focused on sun protection: the avoidance of sun during peak hours, seeking shade, wearing protective clothing and eyewear, and use of sun block. Health-related articles covered varied topics from fitness and nutrition to emotional and behavioral issues. The frequency and percentage of articles related to health in general and skin, in particular, were similar in both magazines. No substantive changes in the frequency of skin articles were observed over time (for both magazines, range per year for sun protection, 1-4).

We identified 6,307 (range, 449-716 per year observed) advertisements in both magazines during the observation period. Nearly 4 of $5(78.1 \%)$ pertained to topics that were not related to health (eg, cleaning products, department stores, food and beverages, vacation destinations). Among the remaining 1,382 advertisements, 538 (8.5\%) focused on skin products, but most $(\mathrm{n}=440,81.8 \%)$ pertained to skin products without SPF, particularly beauty products such as moisturizer and make-up foundation. A total of 64 advertisements were for sun block, representing approximately $1 \%$ of total ads. Only 30 ads were identified for skin products with SPF that were not sun block. Of the 844 health-related advertisements, more than half were related to children's health $(n=429,50.8 \%)$, 280 to adult health $(33.2 \%)$, and 135 (16.0\%) to miscellaneous health-related items. The nature and scope of advertising regarding skin cancer risk reduction was very similar in the 2 magazines during the 11-year period.

\section{Discussion}

Of the most popular parenting magazines in the United States, little attention is given during the spring and summer issues to sun protection in articles and advertisements. The magazines were reviewed during the months of peak ultraviolet exposure, but only 24 of 2,594 articles ( $<1 \%)$ during an 11-year period addressed the topic of sun protection for skin cancer prevention. Furthermore, although advertising in the magazines is pervasive, the extent to which such advertising focuses on products with SPF during the months when ultraviolet radiation is most damaging and dangerous was low.

The etiology of skin cancer is well understood and indicates that overexposure to ultraviolet radiation early in life is a preventable risk factor (3). Studies indicate the need to reduce children's overexposure to ultraviolet radiation from the sun $(3,4)$ and that behaviors that increase risk of skin cancer are prevalent among adolescents $(7-9)$. Parents are responsible for protecting young children from sunburns and less extreme overexposure to ultraviolet radiation as well as for educating them to minimize skin cancer risk behaviors.

Americans are exposed to a substantial amount of information via varied media channels every day. With changes in the coverage of health in the media, the context in which parents obtain health information has changed dramatically. Magazines that target parents can help parents make informed decisions about reducing their children's skin cancer risks in childhood and adolescence. The 2 magazines we reviewed reportedly have approximately 24 million readers (6), who in turn may influence far more children $(10,11)$. These findings suggest that parenting magazines and companies advertising in this medium can do much more to assist parents in making informed decisions about preventing skin cancer risk among youth.

\section{Acknowledgments}

This research was funded in part by a postdoctoral fellowship (no. R25 CA094601) from the National Cancer Institute while Dr C. H. Basch was employed at Columbia University.

\section{Author Information}

Corresponding Author: Corey H. Basch, EdD, MPH, Assistant Professor of Public Health, Department of Public Health, William Paterson University, Wayne, NJ 07470. Telephone: 973-720-2603. E-mail: baschc@wpunj.edu.

Author Affiliations: Grace Clarke Hillyer, Charles E. Basch, Columbia University, New York, New York.

\section{References}

1. Cancer facts and figures. Atlanta (GA): American Cancer Society; 2009.

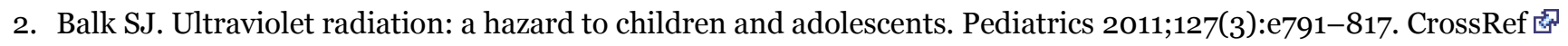
PubMed 迢 
Preventing Chronic Disease I Descriptive Analysis of Articles and Advertisements Pertain... Page 3 of 4

3. Cokkinides VE, Weinstock MA, Cardinez CJ, O'Connel MA. Sun-safe practices in U.S. youth and their parents: role of caregiver on youth sunscreen use. Am J Prev Med 2004;26(2):147-51. CrossRef 㐘 PubMed 㐘

4. Johnson K, Davy L, Boyett T, Weathers L, Roetzheim RG. Sun protection practices for children: knowledge, attitudes, and parent behaviors. Arch Pediatr Adolesc Med 2001;155(8):891-6. PubMed 通

5. Protecting children from the sun. Centers for Disease Control and Prevention. http://www.cdc.gov/cancer/skin/basic_info/children.htm. Accessed July 3, 2012.

6. MRI+ reports: parents and parenting. GfK Mediamark Research and Intelligence, LLC; 2011. http://www.mriplus.com. Accessed July 9, 2012.

7. Geller AC, Colditz G, Oliveria S, Emmons K, Jorgensen C, Aweh GN, Frazier AL. Use of sunscreen, sunburning rates, and tanning bed use among more than 10,000 US children and adolescents. Pediatrics 2002;109(6):100914. CrossRef 密 PubMed 處

8. Demko CA, Borawski EA, Debanne SM, Cooper KD, Stange KC. Use of indoor tanning facilities by white adolescents in the United States. Arch Pediatr Adolesc Med 2003;157(9):854-60. CrossRef 图 PubMed 图

9. Bleyer A, O'Leary M, Barr R, Ries LAG, editors. Cancer epidemiology in older adolescents and young adults 15 to 29 years of age, including SEER incidence and survival: 1975-2000 (NIH publication no. 06-5767). Bethesda (MD): National Cancer Institute; 2006.

10. Simpson AR. The role of the mass media in parenting education. Boston (MA): Center for Health Communication, Harvard School of Public Health; 1997.

11. Hesse BW, Nelson DE, Kreps GL, Croyle RT, Arora NK, Rimer BK, Viswanath K. Trust and sources of health information: the impact of the Internet and its implications for health care providers: findings from the first Health Information National Trends Survey. Arch Intern Med 2005;165(22):2618-24. CrossRef 图 PubMed 逢

\section{Table}

Table. Total Articles $(\mathrm{N}=2,594)^{\text {a }}$ and Advertisements $(\mathrm{N}=6,307)^{\mathrm{b}}$, by Type, Return' in Spring and Summer Issues of Parents and Parenting Magazines (May, June, July, and August), 2000-2010

\begin{tabular}{|c|c|c|}
\hline Type & n (\%) & Range Per Year \\
\hline \multicolumn{3}{|c|}{ Articles } \\
\hline Skin-related & $57(2.2)$ & $2-7$ \\
\hline Sun protection & $24(42.1)$ & $1-4$ \\
\hline Beauty-related & $13(22.8)$ & $0-3$ \\
\hline Other & $16(28.1)$ & $0-5$ \\
\hline Health-related & 509 (19.6) & $25-61$ \\
\hline \multicolumn{3}{|c|}{ Advertisements } \\
\hline Skin products & $538(8.5)$ & $21-79$ \\
\hline Sunless tanners & $4(0.7)$ & $0-3$ \\
\hline Sun block & $64(11.9)$ & $0-16$ \\
\hline Skin products with SPF & $30(5.6)$ & $0-5$ \\
\hline Skin products without SPF & $440(81.8)$ & $18-71$ \\
\hline Health-related & $844(13.4)$ & $55-110$ \\
\hline Adult health & $280(33.2)$ & $16-38$ \\
\hline Child health & $429(50.8)$ & $24-55$ \\
\hline Miscellaneous & $135(16.0)$ & $0-24$ \\
\hline Other & $4,925(78.1)$ & $355-533$ \\
\hline
\end{tabular}


b Range per year, 449-716.

The opinions expressed by authors contributing to this journal do not necessarily reflect the opinions of the U.S.

Department of Health and Human Services, the Public Health Service, the Centers for Disease Control and Prevention, or the authors' affiliated institutions.

The RIS file format is a text file containing bibliographic citations. These files are best suited for import into

bibliographic management applications such as EndNote download is available at each application's web site.

For Questions About This Article Contact pcdeditor@cdc.gov

Page last reviewed: April 04, 2013

Page last updated: April 04, 2013

Content source: National Center for Chronic Disease Prevention and Health Promotion

Centers for Disease Control and Prevention 1600 Clifton Rd. Atlanta, GA 30333, USA

80o-CDC-INFO (80o-232-4636) TTY: (888) 232-6348 - Contact CDC-INFO 